\title{
Enhancing Stability of Thin-Walled Short Steel Channel Using CFRP under Eccentric Compression
}

\author{
Hongyuan Tang, ${ }^{1,2}$ Canjun Wang, ${ }^{3}$ and Ruijiao Wang ${ }^{1}$ \\ ${ }^{1}$ College of Architecture and Civil Engineering, Xihua University, Chengdu, China \\ ${ }^{2}$ Xihua University Key Laboratory of Green Building and Energy Saving, Chengdu, China \\ ${ }^{3}$ State Grid Neijiang Electric Power Supply Company, Neijiang, China
}

Correspondence should be addressed to Hongyuan Tang; tanghyseu@163.com

Received 7 June 2016; Revised 22 August 2016; Accepted 1 September 2016

Academic Editor: Yulin Deng

Copyright (C) 2016 Hongyuan Tang et al. This is an open access article distributed under the Creative Commons Attribution License, which permits unrestricted use, distribution, and reproduction in any medium, provided the original work is properly cited.

\begin{abstract}
This paper presents the experimental and analytical results of eccentrically loaded short cold-formed thin-wall steel channels strengthened with transversely oriented carbon fiber reinforced polymer (CFRP) strips around their web and flange. Seven specimens, each $750 \mathrm{~mm}$ long, were fabricated; the main parameters were the number of CFRP plies (one or two) and the space between the CFRP strips $(50,100$, or $150 \mathrm{~mm}$ ). The application of the CFRP strips results in increases in ultimate load capacity and, with the exception of the most heavily reinforced ( 2 plies at 50 and $100 \mathrm{~mm}$ ), local buckling was observed prior to global buckling. To extend and better understand the experimental work, a companion analytical study was conducted. Comparisons between experimental observations and computed results show that the analyses provided good correlation to actual behavior. In addition, the numerical results explained the observed phenomenon that flange local buckling was constrained to regions between the CFRP strips.
\end{abstract}

\section{Introduction}

Recent work has highlighted improving the stability-related capacity of carbon fiber reinforced polymer (CFRP) reinforced axially loaded steel structures $[1,2]$. In this application, the high stiffness and linear material behavior of the FRP materials used are utilized to provide "bracing" that improves the buckling and postbuckling behavior of steel components [1]. Tests of CFRP-reinforced short circular [3], square [46], open [7, 8], and slender square [9] hot-rolled steel sections have been conducted. Haedir and Zhao [10] reported an experimental study of axial compression of short coldformed circular steel tubes with transverse and longitudinal externally bonded CFRP.

All the previous work shows that the proper CFRP constraints can increase the buckling load capacity of members under axial compression to different degrees. Nevertheless, the improvement of the buckling load capacity of thin-walled members under eccentric compression is rarely considered. Additionally, there is no known research available on the buckling capacity of thin-walled cold-formed short steel channels strengthened with CFRP. Also, the current code, such as AISC Standards [11], is in accordance with the width-thickness ratio of steel. There are compact crosssections, noncompact cross-sections, and slender crosssections. Because of thin-walled cross-section having a relatively large width-thickness ratio, local buckling occurs before reaching the yield strength. In order to prevent this, AISC provision [12] has a limited value of width-thickness ratios.

This paper, therefore, is focused on evaluating the effectiveness of reinforcing thin-walled short steel channels subject to eccentric compression loads with CFRP; buckling behaviors and the associated failure modes are described. The influence of the CFRP thickness and interval of transverse CFRP strips is investigated.

\section{Experimental Program}

2.1. Fabrication of Test Specimens. The test specimen details and measured dimensions are shown in Figure 1 and Table 1. 


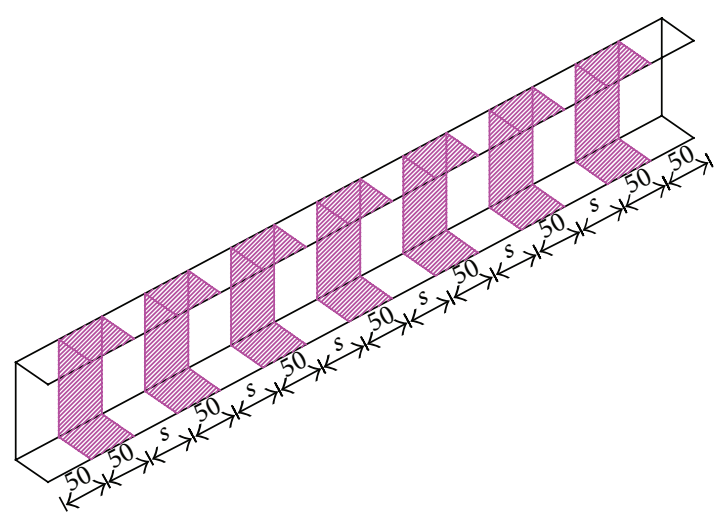

(a)

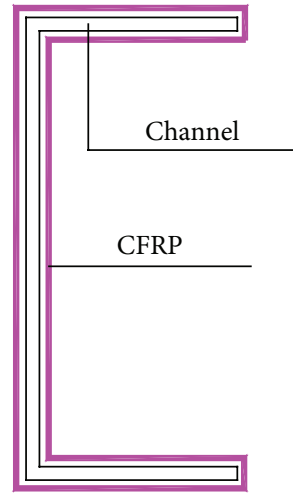

(b)

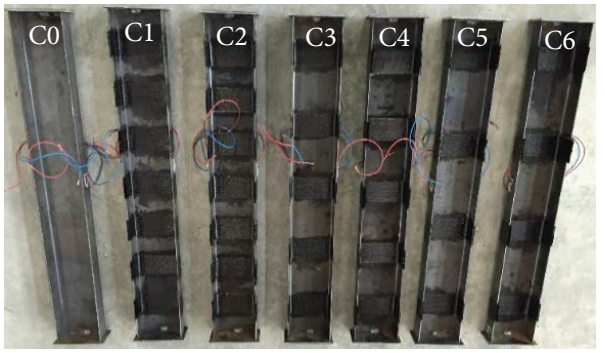

(c)

FIGURE 1: Test specimen. (a) Schematic diagram of external bonded CFRP (number of strips varies depending on $s$ ). (b) CFRP wrapping. (c) Seven specimens.

TABle 1: Parameters of specimens.

\begin{tabular}{lccccc}
\hline Specimen & $\begin{array}{c}h_{w} \\
\mathrm{~mm}\end{array}$ & $\begin{array}{c}b \\
\mathrm{~mm}\end{array}$ & $\begin{array}{c}t \\
\mathrm{~mm}\end{array}$ & $\begin{array}{c}n \\
\text { Plies }\end{array}$ & $\begin{array}{c}s \\
\mathrm{~mm}\end{array}$ \\
\hline C0 & 100.5 & 42.5 & 2.62 & 0 & 0 \\
C1 & 100.0 & 42.8 & 2.63 & 1 & 50 \\
C2 & 101.4 & 42.1 & 2.61 & 2 & 50 \\
C3 & 100.9 & 41.8 & 2.64 & 1 & 100 \\
C4 & 100.6 & 42.6 & 2.63 & 2 & 100 \\
C5 & 100.9 & 41.9 & 2.62 & 1 & 150 \\
C6 & 100.6 & 42.4 & 2.61 & 2 & 150 \\
\hline
\end{tabular}

Specimen C0 was the control specimen having no CFRP; the other six specimens were provided with transversely bonded $50 \mathrm{~mm}$ wide CFRP strips enclosing the entire section (Figure 1). Strips were either one or two plies thick $(n)$ and were provided with a clear spacing of $s=50,100$, or $150 \mathrm{~mm}$ as shown in Table 1. In order to facilitate loading, the two ends of every $750 \mathrm{~mm}$ long specimen were spot welded to a steel plate in order to minimize restraint. The resulting weak axis slenderness ratio, $L / r$, was approximately 62.5 . Web slenderness, $h_{w} / t$, and flange slenderness, $b / t$, were approximately 36.3 and 16.2 , respectively. These values vary marginally with measured dimensions.

2.2. Material Properties. The test specimens were made of Q235 steel whose elastic modulus, yield, and ultimate strength were $202 \mathrm{GPa}, 306 \mathrm{MPa}$, and $418 \mathrm{MPa}$, respectively. The ultimate elongation was 0.33 and Poisson ratio was 0.33 .

The wet lay-up CFRP used had a dry thickness of $0.167 \mathrm{~mm}$ and modulus, strength, and rupture strain of $240 \mathrm{GPa}, 3400 \mathrm{MPa}$, and 0.017 , respectively.

A manufacturer-prescribed saturant was used. The adhesive had an elastic modulus, tension, compressive, and tension-shear strength of $380 \mathrm{GPa}, 43.5 \mathrm{MPa}, 86.0 \mathrm{MPa}$, and $22.06 \mathrm{MPa}$, respectively. The ultimate elongation was 0.022 .

2.3. Specimen Instrumentation. The deformation and strains of specimens were obtained from LVDTs and strain gauges as shown in Figure 2.

At the midheight of specimen, three longitudinally oriented strain gauges were arranged at the middle of the web and flange. The vertical deformation of the specimen was measured by both the hydraulic servo loading control system and LVDT (5). The lateral deformation was measured by LVDT (1). LVDTs (1) and (2) and (3) and (4) were arranged at the midheight of specimen on the web and flange, respectively, while LVDTs (6) and (7) were located at $150 \mathrm{~mm}$ above and below LVDT (2). These latter six instruments were intended to capture the local buckling behavior; meanwhile two video cameras were used to record the whole test process and better capture all observed buckling phenomena.

2.4. Test Setup and Loading Protocol. Testing was conducted using a $500 \mathrm{kN}$ capacity servo hydraulic loading system, as shown in Figure 3. Figure 3(a) shows the top of the 

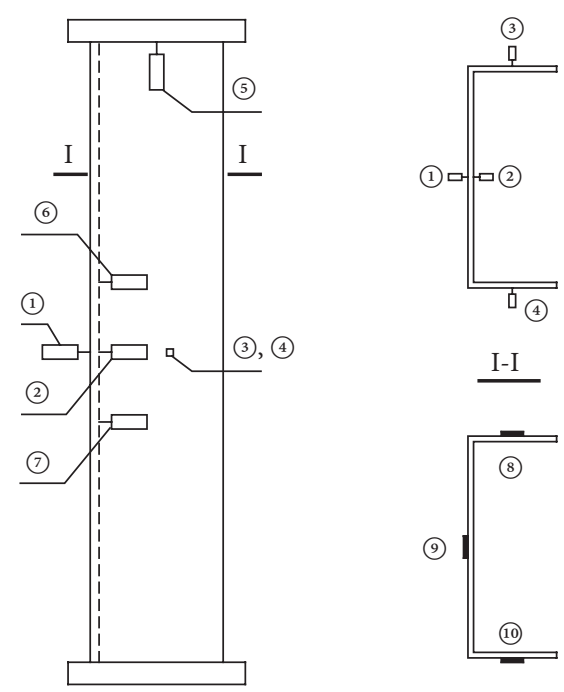

(1), (2), (3), (4), (5), (6), (7): LVDT

(8), (9), (10): strain gauges

FIGURE 2: The arrangement of LVDTs and strain gauges.

component and LVDT (5). Figure 3(c) shows the midheight instrumentation and Figure 3(b) shows the unidirectional "pin" support used at both top and bottom (shown) of the specimen. The two pinned supports were located at the centroid of the end plate: $21.3 \mathrm{~mm}$ from the outside of channel web. The centroid of the control specimen is $10.7 \mathrm{~mm}$ from the outside of channel web, resulting in a $10.6 \mathrm{~mm}$ eccentricity of the compression load with the resulting moment placing the flange tips in compression.

An initial estimate of buckling capacity of specimens was $74.2 \mathrm{kN}$ [13]. A preload of $3 \%$ of this value $(2.2 \mathrm{kN})$ was applied to seat the specimen and loading progressed in $5 \mathrm{kN}$ increments up to $40 \mathrm{kN}$ and in $1 \mathrm{kN}$ increments beyond $40 \mathrm{kN}$. Following each increment, loading was held for 2 or 3 minutes to collect the strain and deformation data.

\section{Experimental Results Analysis}

3.1. Failure Modes. As expected due to the load eccentricity and predicted using the relevant standard [12], the control specimen $\mathrm{C} 0$, exhibited local buckling at the flange tips (Figure 4(a)). This occurred at a load of $57.2 \mathrm{kN}$. However, the six specimens reinforced with CFRP exhibited both flange local buckling (FLB) and flexural torsional buckling (FTB) as described in the following sections.

3.1.1. Flange Local Buckling. The failure modes of specimens $\mathrm{C} 0, \mathrm{Cl}, \mathrm{C} 3, \mathrm{C} 5$, and C6 were flange local buckling (see Figure 4) consistent with the expectation based on the relatively slender flange width-thickness ratio $(b / t=16.2)[12]$ and the load eccentricity. As load was applied beyond initial buckling, specimens tended to twist due to the fact that the flange buckling did not occur at exactly the same height of the specimen. This was particularly evident in specimens C3 and $\mathrm{C} 5$ in which the local flange buckling occurred above
TABLE 2: Summary of load capacity and buckling modes.

\begin{tabular}{lcccc}
\hline Specimen & $\begin{array}{c}P_{y} \\
\mathrm{kN}\end{array}$ & $\begin{array}{c}P_{u} \\
\mathrm{kN}\end{array}$ & $\begin{array}{c}\Delta P \\
\%\end{array}$ & Buckling modes \\
\hline C0 & 52 & 57.23 & - & FLB \\
C1 & 56 & 60.54 & 5.8 & FLB \\
C2 & - & 64.18 & 12.1 & FTB \\
C3 & 54 & 59.58 & 4.1 & FLB \\
C4 & - & 60.65 & 6.0 & FTB \\
C5 & 52 & 59.35 & 3.7 & FLB \\
C6 & 52 & 60.11 & 5.0 & FLB \\
\hline
\end{tabular}

TABLE 3: Comparison of buckling load capacity of specimens.

\begin{tabular}{lccc}
\hline Specimen & $\begin{array}{c}P_{\mathrm{EXP}} \\
\mathrm{kN}\end{array}$ & $\begin{array}{c}P_{\mathrm{FEM}} \\
\mathrm{kN}\end{array}$ & $\Delta P=\left(P_{\mathrm{FEM}}-P_{\mathrm{EXP}}\right) / P_{\mathrm{EXP}}$ \\
\hline $\mathrm{C} 0$ & 57.23 & 58.72 & $2.6 \%$ \\
$\mathrm{C} 1$ & 60.54 & 62.37 & $3.0 \%$ \\
$\mathrm{C} 2$ & 64.18 & 66.44 & $3.5 \%$ \\
$\mathrm{C} 3$ & 59.58 & 61.58 & $3.3 \%$ \\
$\mathrm{C} 4$ & 60.65 & 62.09 & $2.4 \%$ \\
$\mathrm{C} 5$ & 59.35 & 60.95 & $2.7 \%$ \\
$\mathrm{C} 6$ & 60.11 & 61.57 & $2.4 \%$ \\
\hline
\end{tabular}

and below the midheight-located CFRP strip on each flange (Figure 4(e)).

The local and global behaviors of specimens $\mathrm{C} 0, \mathrm{C} 1, \mathrm{C} 3$, C5, and C6 were similar. Capacities of the CFRP-wrapped specimens, as shown in Table 3, were marginally greater than that of $\mathrm{C} 0$.

3.1.2. Flexural Buckling. Specimens $\mathrm{C} 2$ and $\mathrm{C} 4$ exhibited flexural torsional buckling (FTB) prior to their flanges buckling; their final failure modes are shown in Figure 5. These specimens (a) had the greatest amount of CFRP applied (Table 1) and (b) were reinforced at their midheight-the location of the greatest moment due to load eccentricity. These effects combined to sufficiently strengthen the midheight flanges so that they resisted local buckling. Since local buckling was moved away from the midheight, the stress fell sufficiently to allow flexural buckling of the specimen to become manifest. Capacities of these specimens (Table 2) were greater than that of $\mathrm{C} 0$ and marginally greater than those specimens exhibiting flange buckling.

\subsection{Load-Displacement Curve}

3.2.1. Web Load-Displacement Curve. Load-displacement curves of web point (1) of specimens are shown in Figure 6. Due to the reason that the rapid increase of the web horizontal displacement after the overall buckling may cause damage to LVDTs, the dropped part of load-displacement curves in Figure 6 is incomplete. But that does not influence results of the test.

From Figures 6(a) and 6(b), it was observed that the load-deformation curve obtained by the experiment for all strengthened members exhibited a linear elastic behavior 


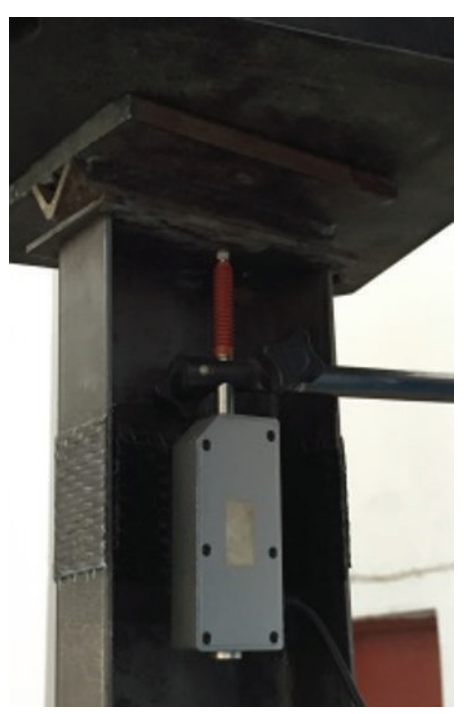

(a)

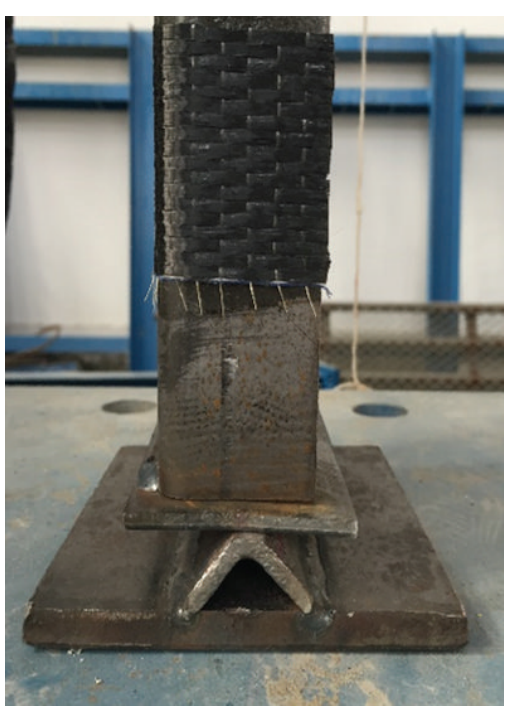

(b)

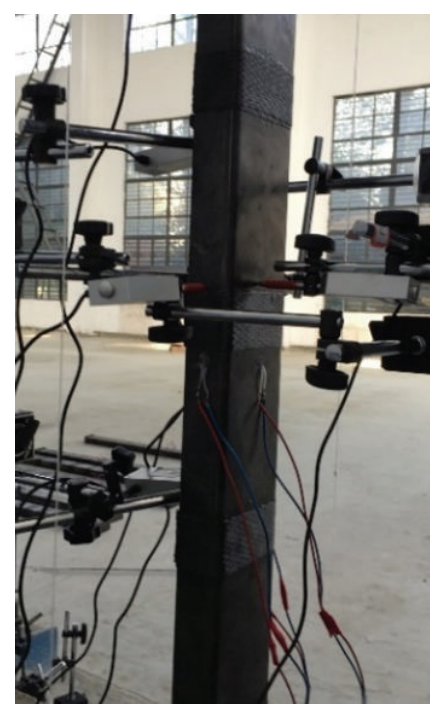

(c)

Figure 3: Test setup.

until it reached the failure load of control specimen, followed by an inelastic behavior when increasing the load.

\subsubsection{Flange Load-Deformation Curve. Load-deformation} curves of flange point (3) at specimens are shown in Figure 7. Due to the same reason of the web load-deformation curve, flange load-deformation curves are incomplete.

As can be seen from Figures 7(a) and 7(b), the smaller the space between the externally bonded CFRP strips, the smaller the horizontal deformation of flange point (3). Although the load increased rapidly, the deformation of flange point (3) increased very difficultly when the load reached a certain value. At the last part of the curve, the reverse deformation occurred when the load reached a certain stage. That indicated that torsion appeared.

3.3. Experimental Data Summary. The local buckling, overall buckling capacity, and buckling modes of all specimens are listed in Table 2.

In Table 2, $P_{y}$ and $P_{u}$ are the flange buckling and overall buckling load, respectively. And $\Delta P$ equals $P_{u}$ of each specimen minus $P_{y}$ of control member $\mathrm{C} 0$. Apart from specimens $\mathrm{C} 2$ and $\mathrm{C} 4$, others caused occurrence of the flange local buckling first. When increasing the load, finally, specimens C2 and $\mathrm{C} 4$ caused occurrence of overall buckling prior to flanges local buckling. This irrational phenomenon did not agree with the standard [12]. It substantially attributed to specimens C2 and C4 strengthened with two-ply CFRP strips whose clear space was $50 \mathrm{~mm}$ and $100 \mathrm{~mm}$, respectively. The phenomenon can also explain that the proper CFRP constraints can effectively confine local buckles and deformation of the flange, which resulted in the delay of local buckling of thinwalled specimen.

As shown in Table 2, when the space of CFRP strips, such as specimens $\mathrm{C} 1, \mathrm{C} 2, \mathrm{C} 3$, and $\mathrm{C} 4$, is not more than $100 \mathrm{~mm}$, increasing the number of CFRP layers has a significant effect on improving the flange local buckling capacity. Compared to the control member $\mathrm{C} 0$, specimens $\mathrm{C} 1$ and $\mathrm{C} 3$ enhanced their flange local buckling capacity by $7.7 \%$ and $3.8 \%$, respectively. Nevertheless, the flange local buckling capacity of those members wrapped with $150 \mathrm{~mm}$ spacing of CFRP strips, such as $\mathrm{C} 5$ and $\mathrm{C6}$, did not increase yet.

From the above observations, it can be noted that when increasing the spacing of CFRP strips, the unbonded area becomes more and it is subjected to maximum strain during loading and consequently buckling of steel occurred in the unwrapped zone due to the absence of confinement pressure provided by the CFRP composites.

3.4. Effect of CFRP Strips Space and Layer on Ultimate Load Capacity. The influence of CFRP strips layer and space on ultimate load capacity of specimens can be directly indicated with the relationship of the space $s$ to the web height $h_{w}$ ratio and the buckling load, as shown in Figure 8. The relationship between the flange local buckling load and the $s / h_{w}$ ratio is shown in Figure 8(a). Given that specimens C2 and C4 firstly caused occurrence of overall buckling prior to the flange local buckling, their overall buckling load was used as their local buckling load. Figure $8(\mathrm{~b})$ indicates the relationship between the overall buckling load and $s / h_{w}$ ratio.

\section{Finite Element Numerical Simulation Analyses}

4.1. Finite Element Modelling of Specimens. The generalpurpose finite element software package ANSYS 12.0 [14] was employed to simulate the test cold-formed thin-walled steel channels in this study. The cold-formed thin-walled steel channel was modelled using element solid 45. CFRP adopted element shell 181; at the same time, the common node was used as the bond between material steel and CFRP. Because 

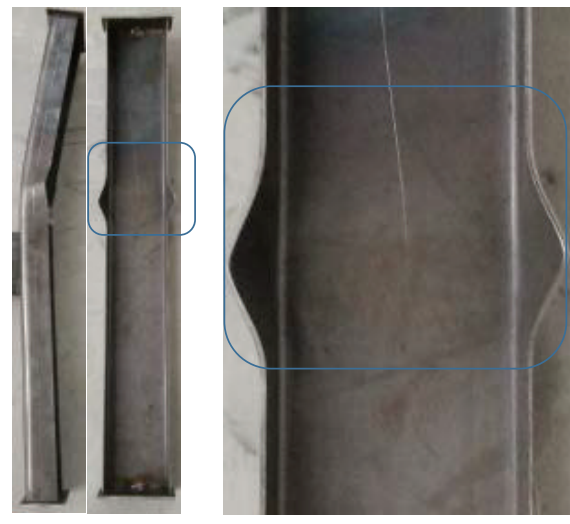

(a) $\mathrm{C} 0$
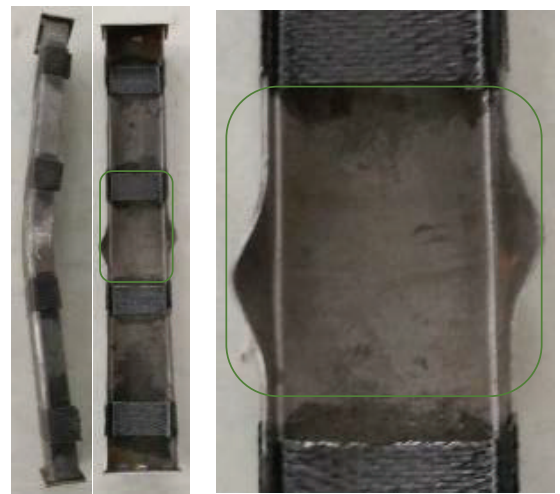

(c) $\mathrm{C} 6$
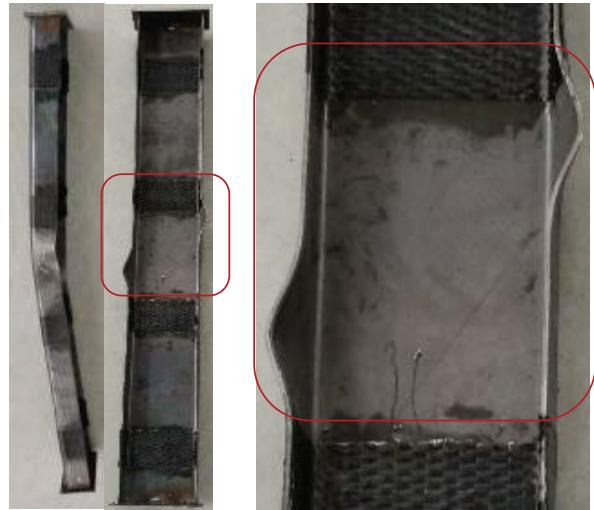

(b) C5
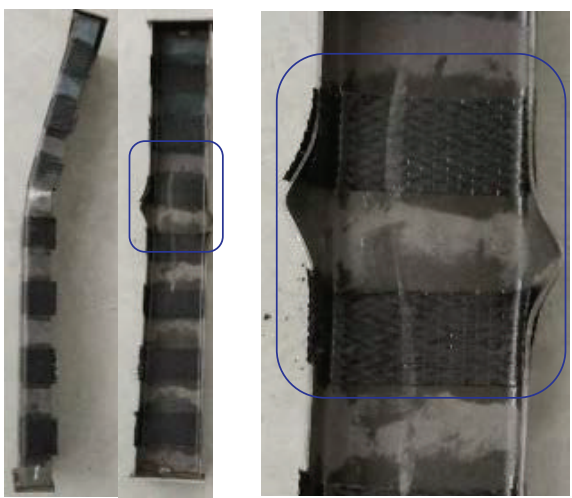

(d) $\mathrm{Cl}$
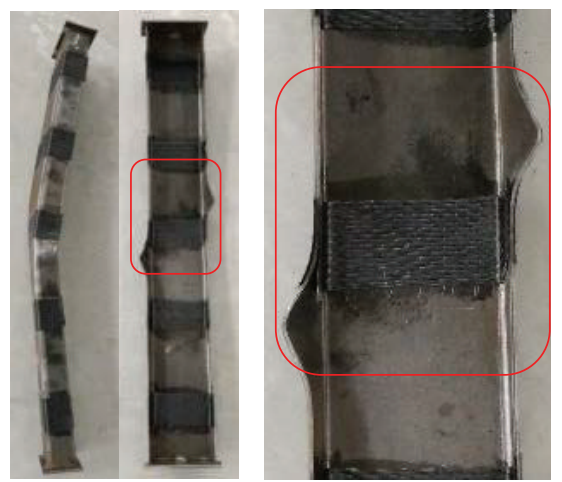

(e) $\mathrm{C} 3$

FIgURE 4: Failure modes of specimens exhibiting flange local buckling.

the test and the numerical simulation are comparative analyses of seven specimens, this paper can only consider the initial geometric imperfections of specimens without the residual stress. Therefore, for the finite element analysis to capture the experimental behavior realistically, a geometric imperfection was included in the finite element model. And sevenspecimen geometric imperfection was assumed to be $l / 1000$. When the initial imperfections were applied, components should be analyzed for eigenvalue buckling, and the firstorder buckling modes can be obtained. The initial geometric imperfections can be achieved by updating the node coordinates by the command UPGEOM.
Numerical simulations of the literature [15] shows that the calculation error of constitutive relation of steel is less than $0.1 \%$, whether considering the strain-hardening or not while using the double broken line model. Therefore, this paper adopted the ideal elastic-plastic model as the material constitutive relationship when the finite element simulation was conducted. Material properties of steel and CFRP were consistent with the experiment, as shown in Table 1.

In the finite element analysis, the midpoint of load action line was conceived as the dominated node. By executing the command CERIG, the other nodes in the end face of the component were coupled with the dominated node. That made 

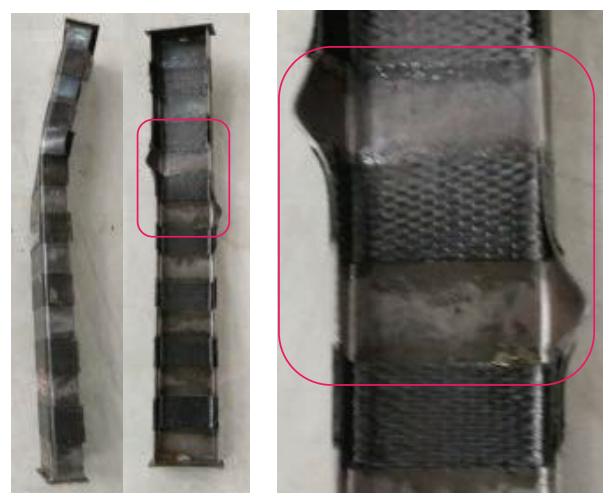

(a) $\mathrm{C} 2$
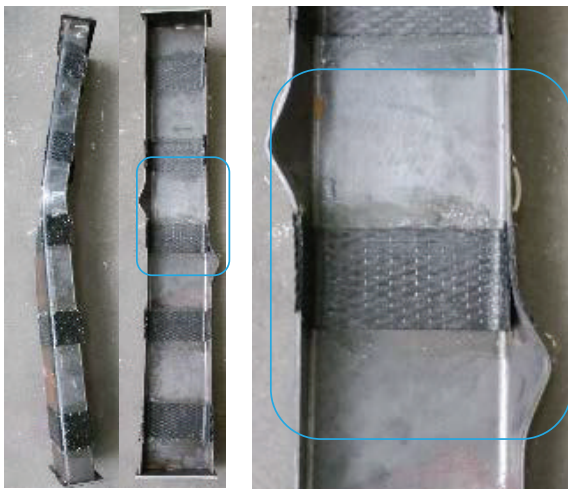

(b) $\mathrm{C} 4$

FIGURE 5: Failure modes of specimens exhibiting flexural torsional buckling prior to flange local buckling.
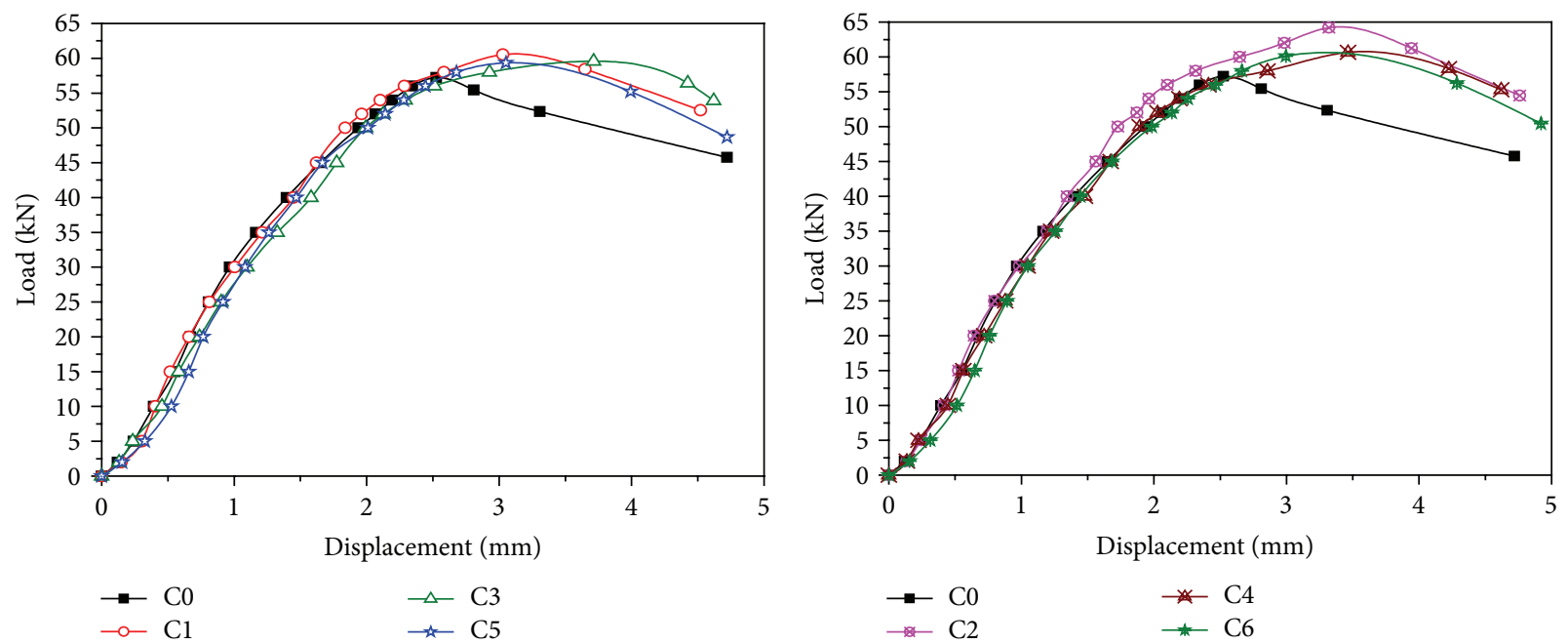

(a) One-ply CFRP

(b) Two-ply CFRP

Figure 6: Web load-deformation curves.

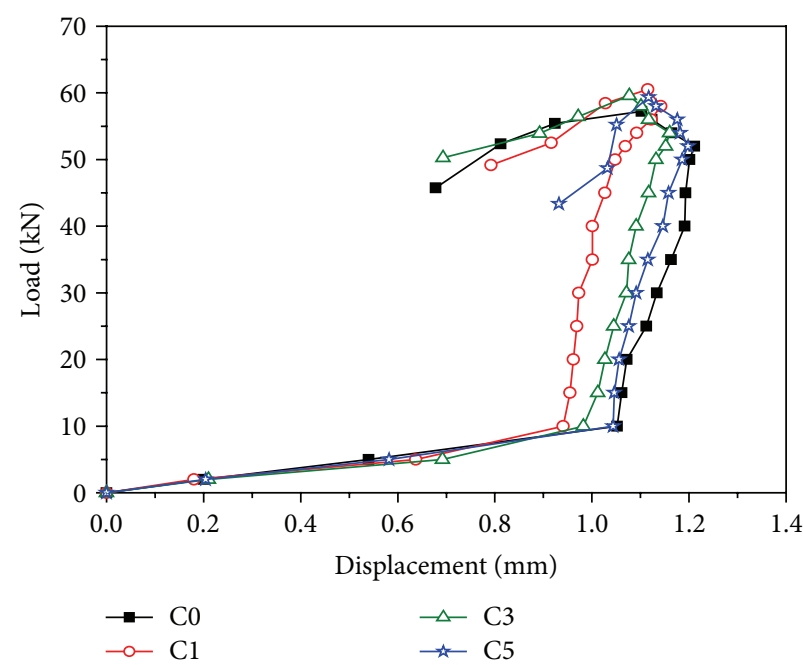

(a) One-ply CFRP

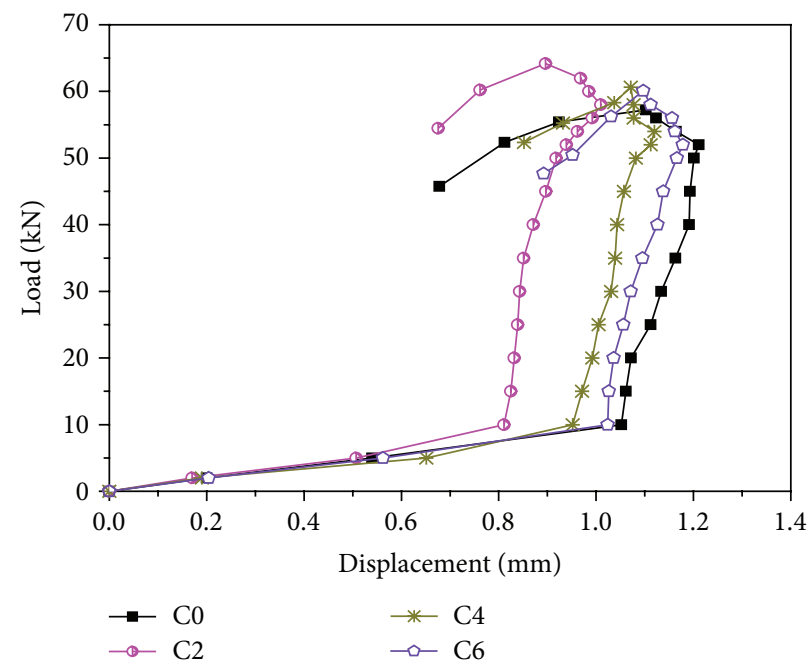

(b) Two-ply CFRP

FIgURE 7: Flange load-deformation curves. 


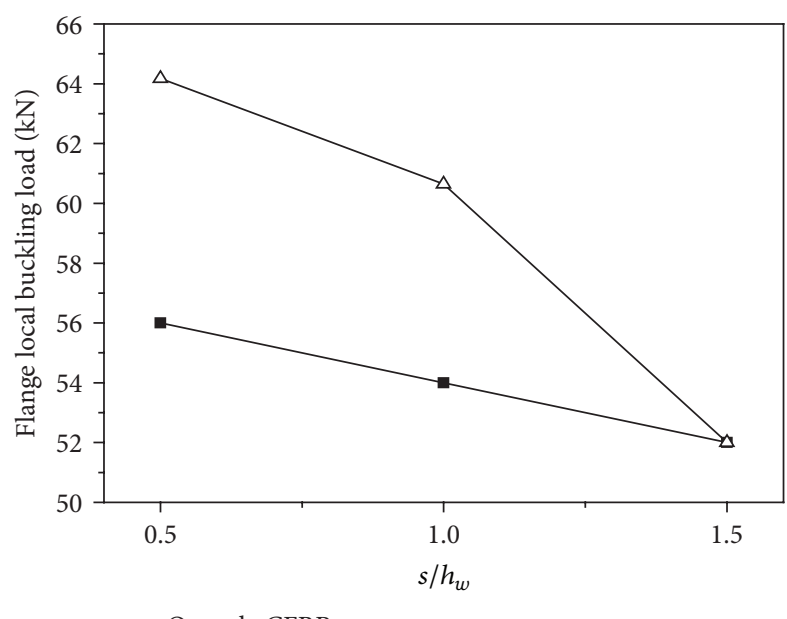

$\rightarrow$ One-ply CFRP $\triangle-$ Two-ply CFRP

(a)

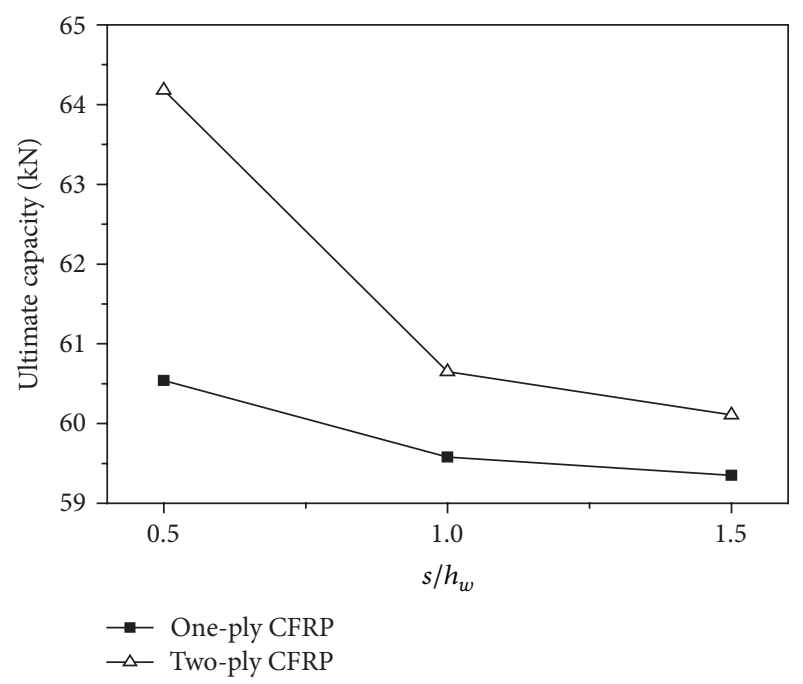

(b)

FIGURE 8: The relationship of buckling load capacity and $s / h_{w}$ ratio

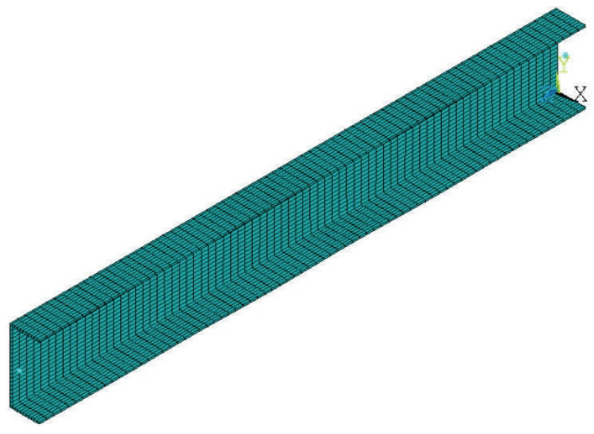

(a) Control specimen

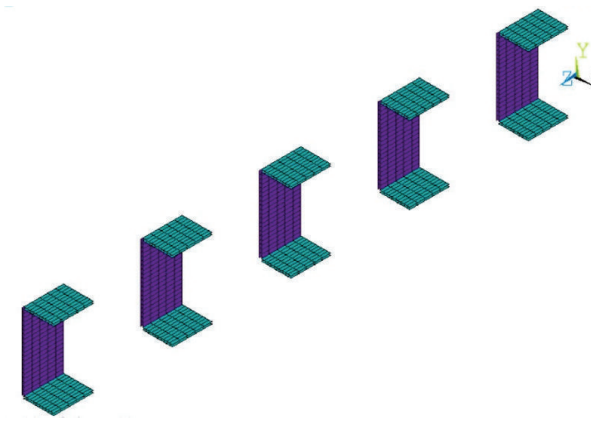

(c) Spacing $100 \mathrm{~mm}$

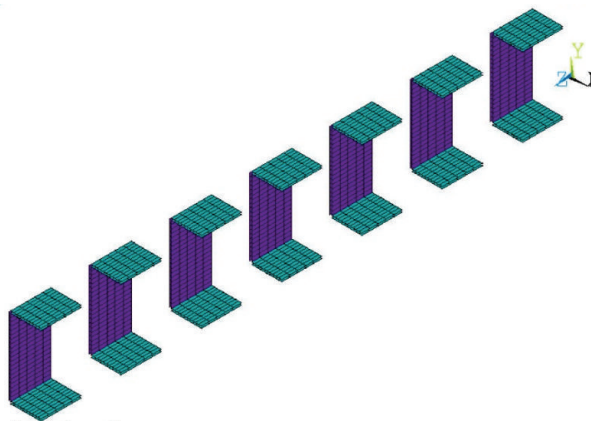

(b) Spacing $50 \mathrm{~mm}$

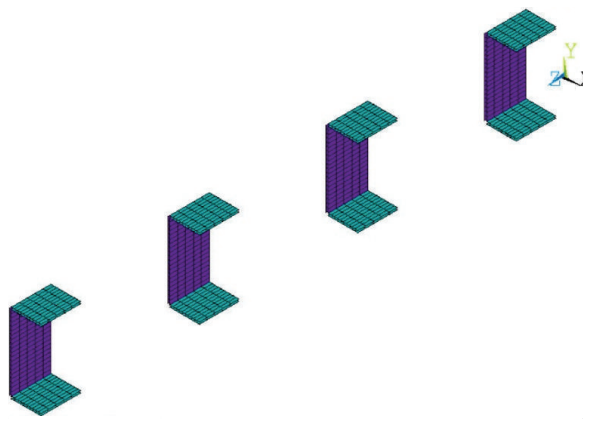

(d) Spacing $150 \mathrm{~mm}$

FIGURE 9: Finite element model.

rigid surfaces forming at both ends of the specimen. Furthermore, the boundary condition of the theoretical model was similar to that of the experimental end plate. Finite element models are shown in Figure 9.

4.2. Numerical Simulation Results. The Von-Mises stress of each model buckling and failure modes were derived from the finite element numerical simulation as shown in Figure 10.
From Figure 10, the stress contour of specimen with $s / h_{w} \leq 1$, such as specimens C1, C2, C3, and C4, exhibited a phenomenon; that is, high stress regions of flange edges always appeared at intervals of CFRP strips. It was indicated that the CFRP may play a significant role in resisting the flange local buckling like the "brace" if externally bonded CFRP strips space is appropriate. It not only can explain the maximum local bulge of the flange happened at the CFRP 

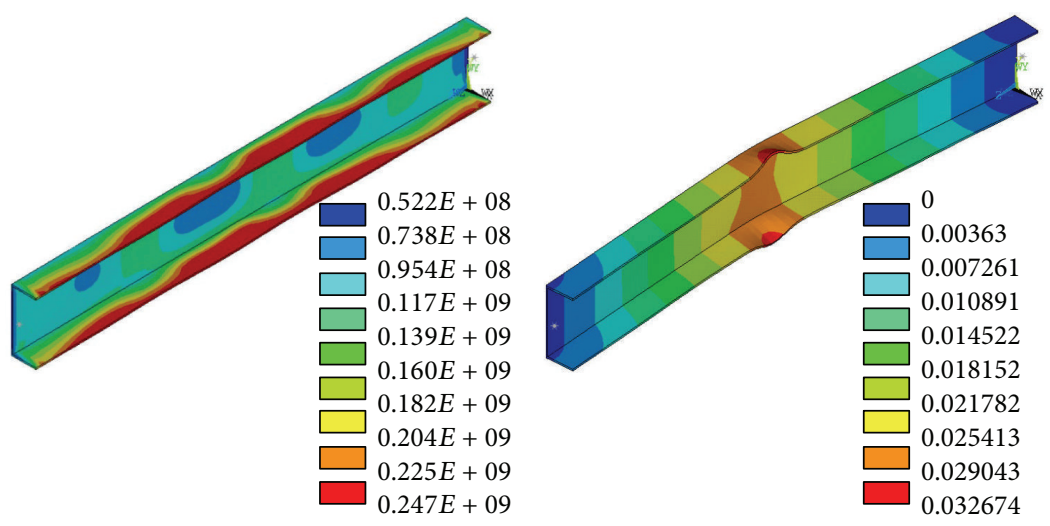

(a) $\mathrm{C} 0$
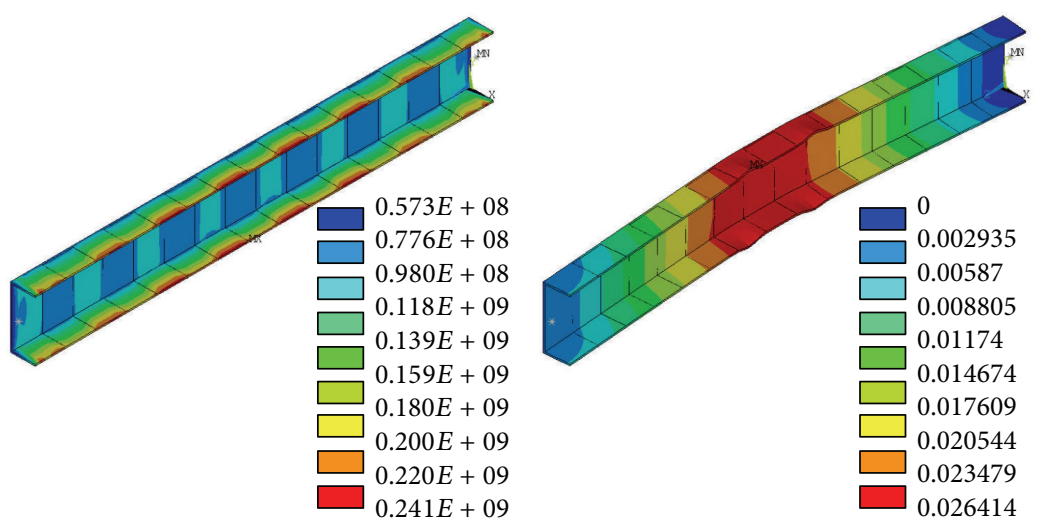

(b) $\mathrm{Cl}$
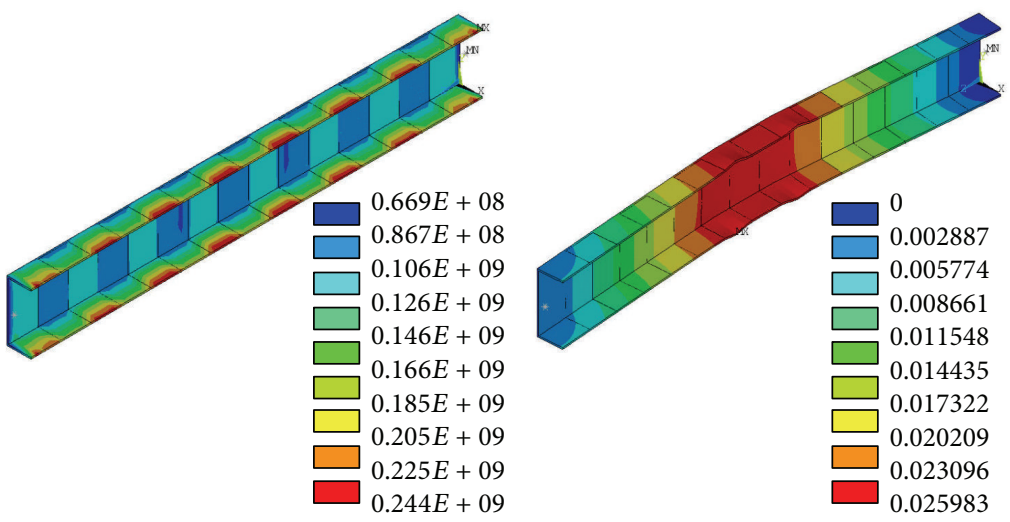

(c) $\mathrm{C} 2$
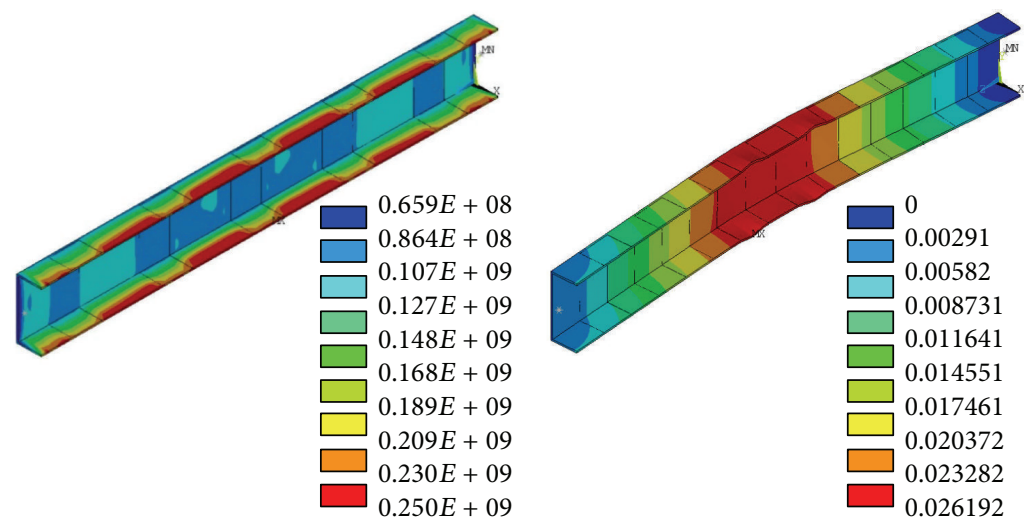

(d) $\mathrm{C} 3$

Figure 10: Continued. 


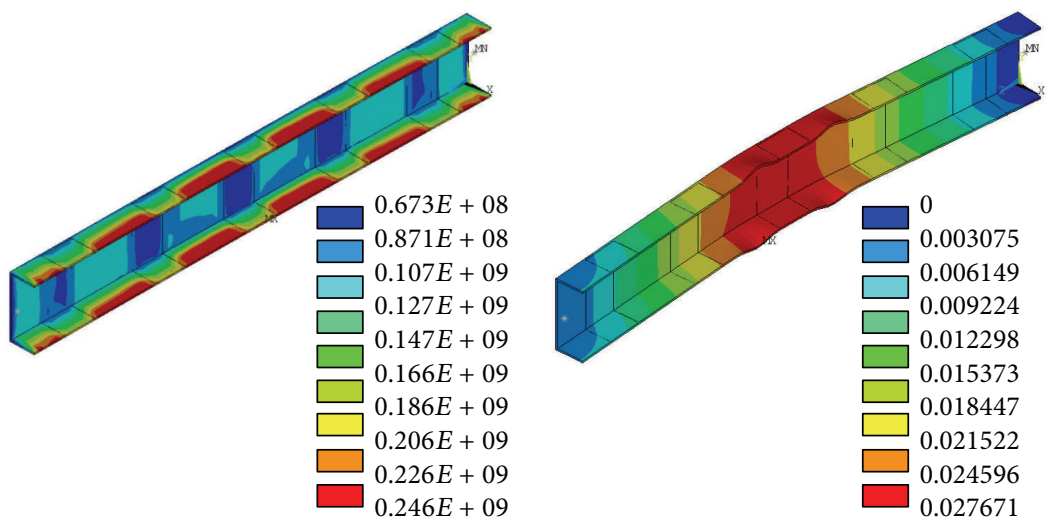

(e) $\mathrm{C} 4$

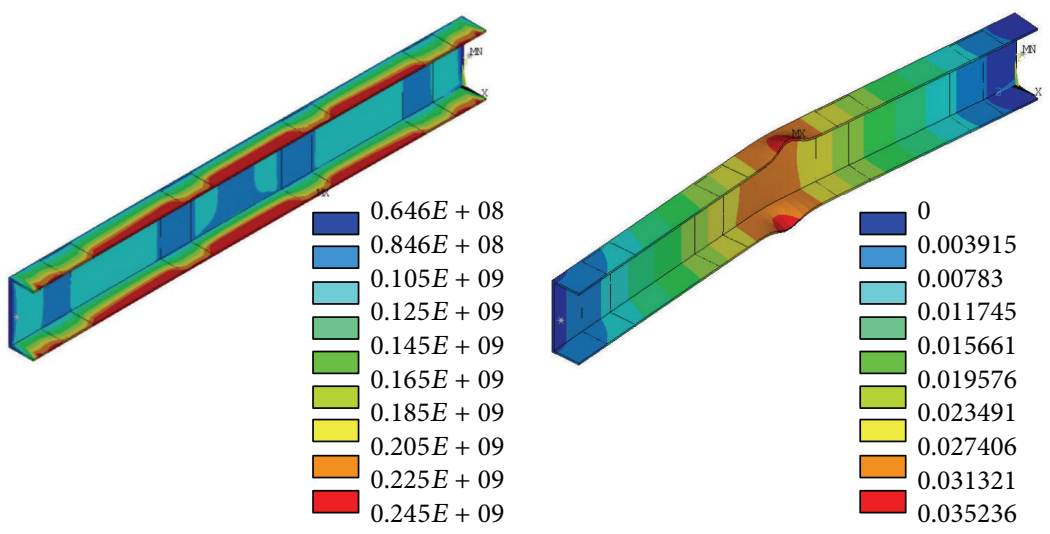

(f) $\mathrm{C} 5$

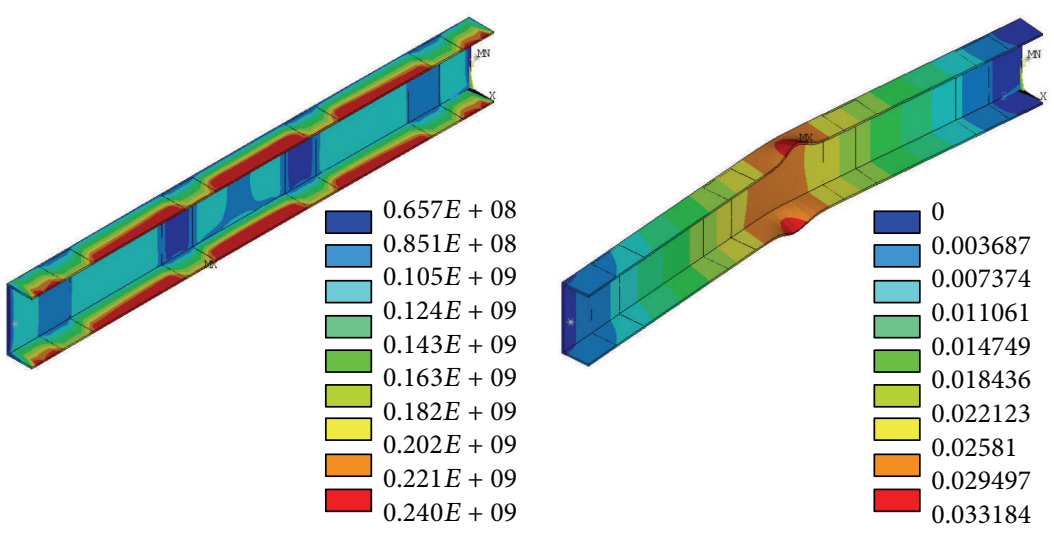

(g) $\mathrm{C} 6$

Figure 10: The Von-Mises graph and failure mode of components.

neutral position, but can also explain why the local buckling capacity can obtain certain extent promotion in the experiment.

\subsection{Comparison between Finite Element Numerical Simula-} tion and Experimental Results. The ultimate load capacity obtained by the numerical simulation fairly agreed with the corresponding experimental results, as shown in Table 3 . The biggest difference between the experimental results and the FEM results is specimen C2, which is 3.5\%. However, others are all below $3.0 \%$. Therefore, finite element models can well simulate the buckling capacity of thin-walled steel members with CFRP and also prove the validity of experimental results.

Also, through the nonlinear analysis, load-deformation curves obtained by experimental and FEM results are shown in Figure 11.

The load-deformation curve obtained by numerical simulation for all strengthened members exhibited linear elastic behavior until it reached the failure load, followed by the inelastic behavior with load increasing. In addition to this, those behaviors were in good agreement with the experimental results. Compared with experimental results, all of 


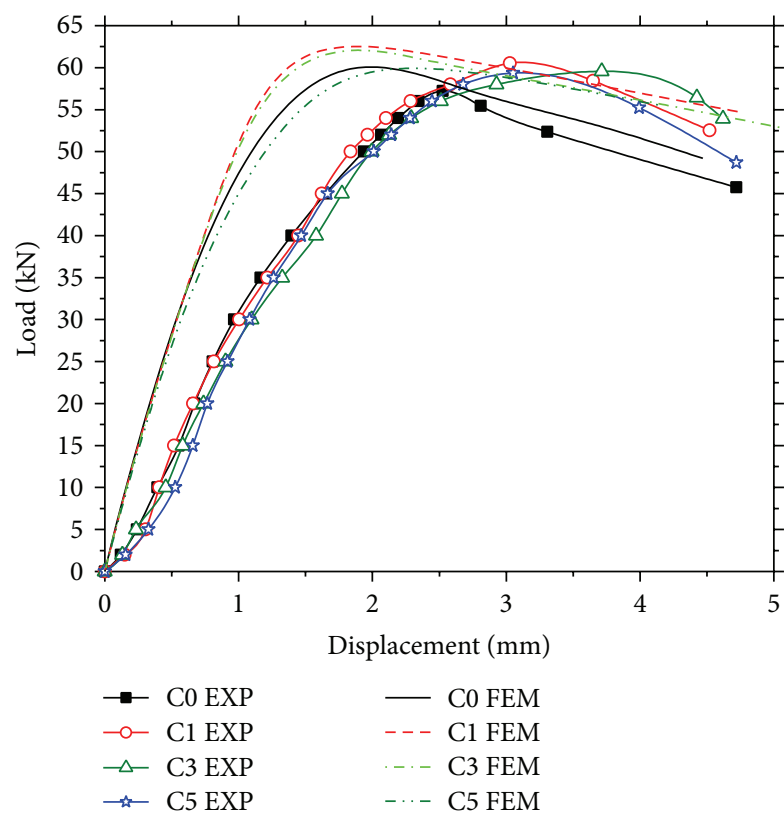

(a) Specimen with one-ply CFRP

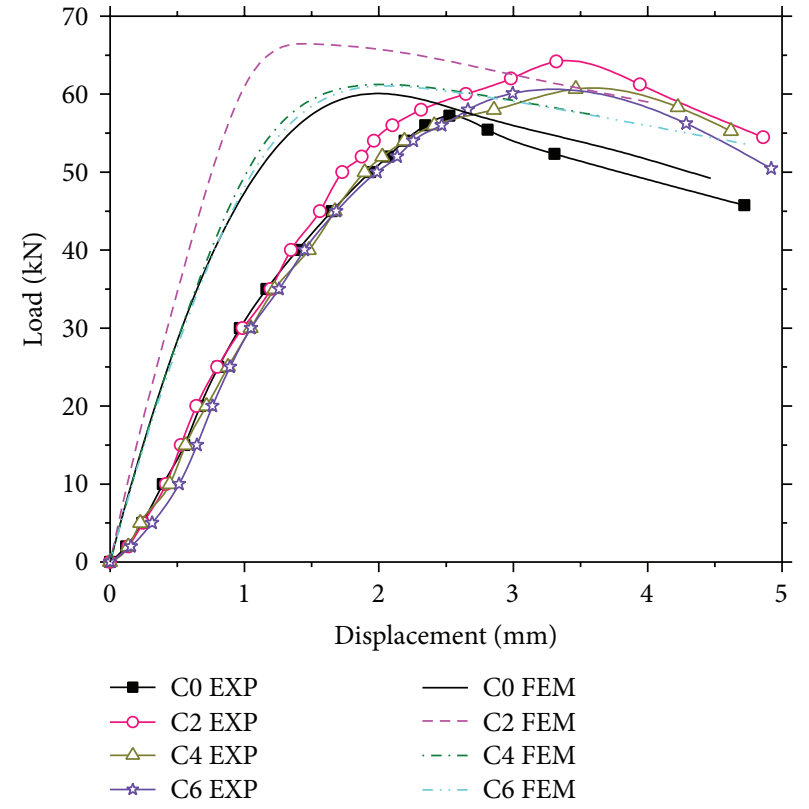

(b) Specimen with two-ply CFRP

FIGURE 11: Load-deformation relationship curves.

the displacements of the FEM results are smaller under the same load whenever the specimen is elastic or not. There may exist two reasons to explain this: first of all, the CFRP and steel shared the same node in the finite element analysis and, second, the specimen has fabrication errors inevitably in the test.

\section{Conclusions}

This paper has presented a study of the potential of strengthening short steel cold-formed thin-walled channels by using externally bonded CFRP sheets. A series of eccentric compression tests of steel channels reinforced by high-strength CFRP sheets was conducted to study the local buckling and overall buckling behavior and strength of the steel channels. The finite element modelling program ANSYS ver. 12.0 was used for this study. From the eccentric load tests and FEM analysis, the structural behavior was observed, and the retrofitting effect of CFRP ply and interval distance were compared. Conclusions derived in this study are as follows.

(1) The specimen webs and flanges transversely bonded with CFRP strips are a little similar to increase the cross-section torsional moment of inertia, which can delay the specimen flexural torsional buckling, so as to improve the ultimate load capacity. Also, through confining the flange deformation in the compressive stress region in cross-section, the CFRP can delay the flange local buckling of thin-walled short steel channels.

(2) As for cold-formed thin-walled steel channel reinforced with transversely bonded CFRP strips, when specimens have the same CFRP layer, the smaller the CFRP strips space, the greater the improvement of the buckling capacity. When the CFRP strips space is $50 \mathrm{~mm}$ and the layer is two, the ultimate buckling load capacity of the specimen under eccentric compression can be totally increased by $12.1 \%$.

(3) When the CFRP strips space is larger than the web height of cold-formed thin-walled short steel channel, that is, $s / h_{w}>1$, the reinforced CFRP does not have a significant improvement in the buckling load capacity of the component. While the space is smaller than the web height, that is, $s / h_{w} \leq 1$, the higher number of CFRP layers, the more enhancement of buckling load capacity.

(4) During the experimental loading process, there was not any debonding or slip between steel and CFRP; therefore, the method that adopted common nodes between the steel and CFRP in finite element numerical simulation has a limited impact on the analytical results.

(5) This paper only analyzes the buckling behavior of the cold-formed thin-walled short steel channels in the situation that transversely bonded CFRP strips under eccentric compression. As for the other methods using CFRP reinforced this kind of steel member, such as longitudinally bonded CFRP or no space between the CFRP strips, further work is needed to examine the behavior of that situation.

\section{Notations}

$h_{w}$ : Height of the web

$b$ : The flange width

$t$ : The specimen thickness

$\lambda$ : Slenderness ratio of weak axis 
n: Ply number of externally bonded CFRP

$s$ : Clear interval between CFRP strips

$\varepsilon_{k}$ : Square root of 235 divided by $f_{y}$.

\section{Competing Interests}

The authors declare that they have no competing interests.

\section{Acknowledgments}

This study was generously funded by Xihua University key fund (z1120634), the Open Research Fund of Xihua University Key Laboratory of Green Building and Energy Saving (szjj2015-073), and scientific research fund of Sichuan provincial education department $(16206491,12206444)$. The authors are most grateful to these organizations for their valuable support.

\section{References}

[1] K. A. Harries, "Enhancing stability of steel structural sections using FRP composites," in Rehabilitation of Metallic Civil Infrastructure Using Fibre Reinforced Polymer Composites, V. Karbhari, Ed., Woodhead Publishing Series in Civil and Structural Engineering no. 51, chapter 5, pp. 117-139, 2014.

[2] X.-L. Zhao and L. Zhang, "State-of-the-art review on FRP strengthened steel structures," Engineering Structures, vol. 29, no. 8, pp. 1808-1823, 2007.

[3] J. G. Teng and Y. M. Hu, "Behaviour of FRP-jacketed circular steel tubes and cylindrical shells under axial compression," Construction and Building Materials, vol. 21, no. 4, pp. 827-838, 2007.

[4] A. Shaat and A. Fam, "Axial loading tests on short and long hollow structural steel columns retrofitted using carbon fibre reinforced polymers," Canadian Journal of Civil Engineering, vol. 33, no. 4, pp. 458-470, 2006.

[5] J.-W. Park, H.-J. Yeom, and J.-H. Yoo, "Axial loading tests and FEM analysis of slender square hollow section (SHS) stub columns strengthened with carbon fiber reinforced polymers," International Journal of Steel Structures, vol. 13, no. 4, pp. 731743, 2013.

[6] M. C. Sundarraja, P. Sriram, and G. Ganesh Prabhu, "Strengthening of hollow square sections under compression using FRP composites," Advances in Materials Science and Engineering, vol. 2014, Article ID 396597, 19 pages, 2014.

[7] K. A. Harries, A. J. Peck, and E. J. Abraham, "Enhancing stability of structural steel sections using FRP," Thin-Walled Structures, vol. 47, no. 10, pp. 1092-1101, 2009.

[8] S. Bekey, P. Feng, L.-P. Ye, and Y.-H. Zhang, "Experimental study on FRP fast anti-buckling strengthening technique for axial compressive steel members," Engineering Mechanics, vol. 29, no. 6, pp. 105-113, 2012 (Chinese).

[9] A. Shaat and A. Z. Fam, "Slender steel columns strengthened using high-modulus CFRP plates for buckling control," Journal of Composites for Construction, vol. 13, no. 1, pp. 2-12, 2009.

[10] J. Haedir and X.-L. Zhao, "Design of short CFRP-reinforced steel tubular columns," Journal of Constructional Steel Research, vol. 67, no. 3, pp. 497-509, 2011.

[11] AISI Standard, Supplement to the North American Specification for the Design of Cold-Formed Steel Structural Members, American Iron and Steel Institute, Washington, DC, USA, 2001.
[12] AISC, Steel Construction Manual, vol. 2, American Institute of Steel Construction, 13th edition, 2005.

[13] Standards China, "Technical code of cold-formed thin-wall steel structures," Tech. Rep. GB50018-2002, Standards China, Beijing, China, 2002 (Chinese).

[14] W. Xinming, ANSYS in Numerical Analysis of Engineering Structural, China Transportation Press, Beijing, China, 2007 (Chinese).

[15] G. Li, Y. Wang, S. Chen, and F. Sun, "Parametric analysis of ultimate bearing capacity of Q460 high strength steel welded box columns under axial compression," Journal of Building Structures, vol. 32, no. 11, pp. 149-155, 2011 (Chinese). 

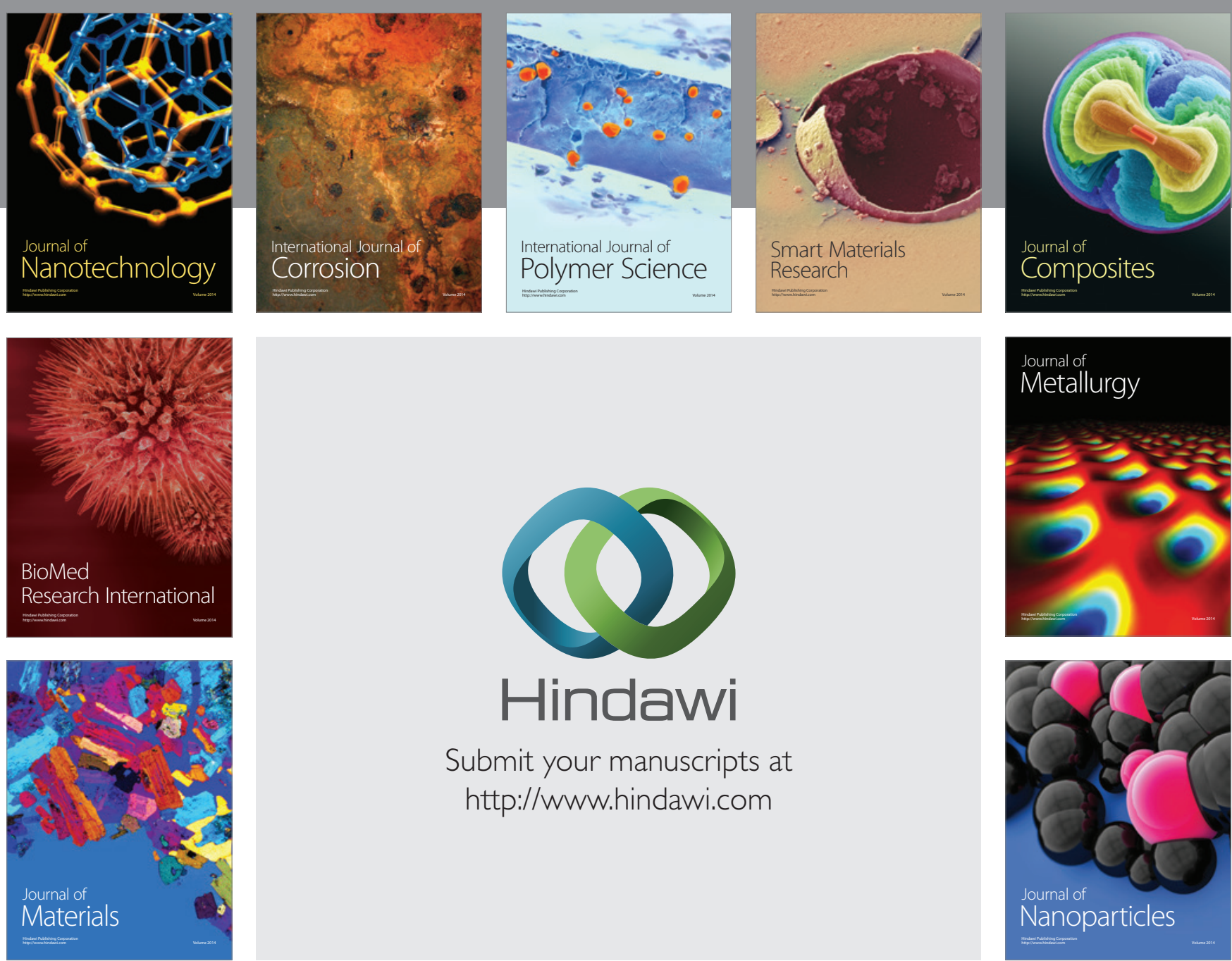

\section{Hindawi}

Submit your manuscripts at

http://www.hindawi.com

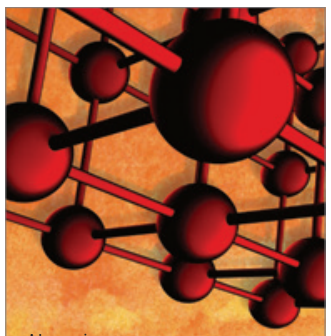

Materials Science and Engineering
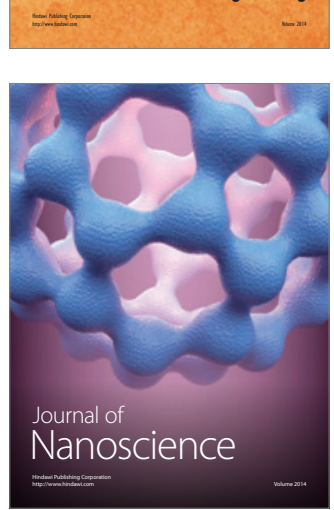
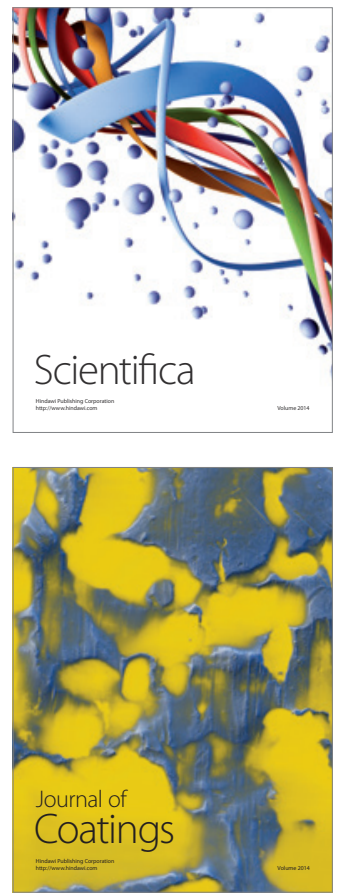
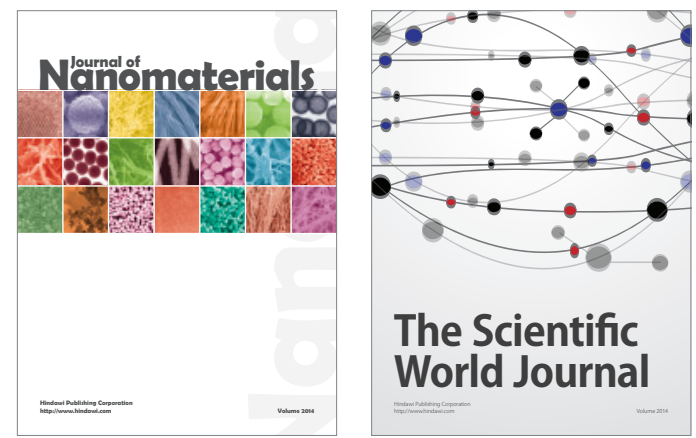

The Scientific World Journal
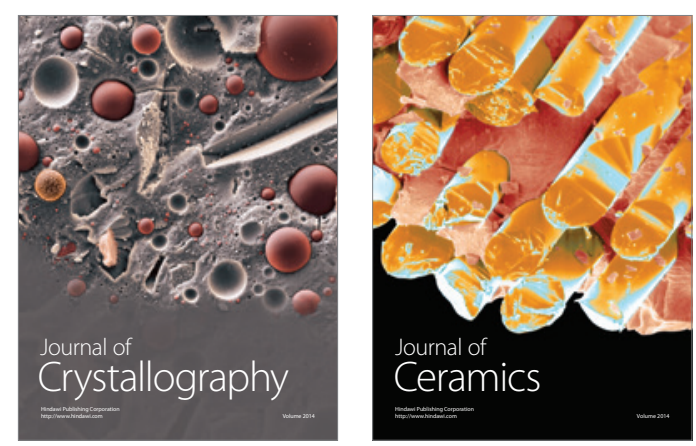
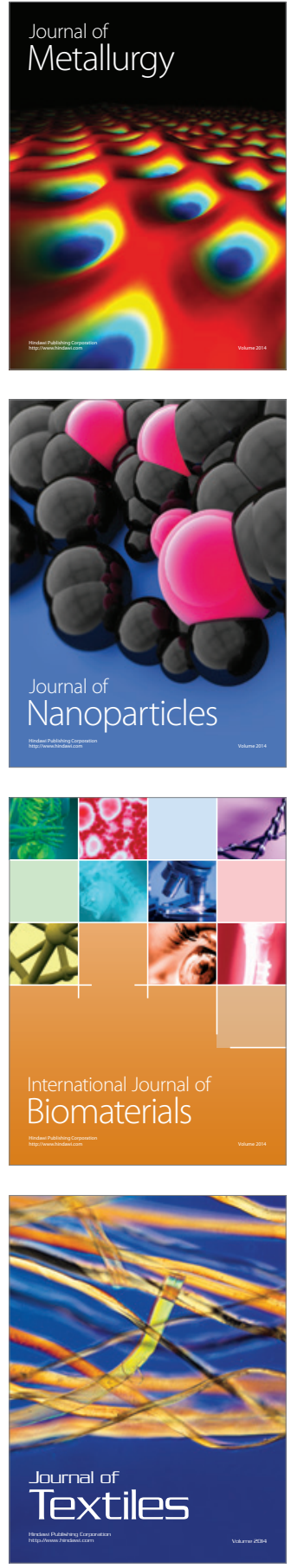